\title{
Erratum to: A GIS-based study on channel variation, erosion and deposition along the bank of Dibru Saikhowa National Park (1967-2016), Assam, India
}

\author{
Rituraj Neog ${ }^{1}$
}

Published online: 24 August 2017

(c) Springer International Publishing AG 2017

\section{Erratum to: Sustain. Water Resour. Manag \\ DOI 10.1007/s40899-017-0131-6}

In the original version of the article there was a duplication of text. The last paragraph in chapter "Erosion and deposition" was the same as already included in chapter "Topography of the region". In chapter "Erosion and deposition" the last grid was updated.

The original article has been corrected.

The online version of the original article can be found under doi:10.1007/s40899-017-0131-6.

Rituraj Neog

rituraj.neog08@gmail.com

1 Center for Studies in Geography, Dibrugarh University,

Dibrugarh, Assam, India 